\title{
Rehabilitación atornillada de dos incisivos inferiores mediante un único implante. A propósito de un caso
}

\author{
Vim Quintana, A.* ; Cervera Echeverría, S.**
}

*Práctica privada en Prótesis Bucal y Endodoncia en Girona ; ** Práctica privada en Periodoncia e Implantología en Girona

\section{Introducción}

La rehabilitación de uno o múltiples dientes mediante implantes osteointegrados y prótesis implantosoportadas es, desde hace años, el tratamiento de elección para la mayoría de odontólogos. Gracias a ellos, podemos realizar restauraciones más predecibles, más cómodas y menos invasivas.

\section{Objetivo}

Restablecer la función, estética y salud oral de nuestra paciente mediante la rehabilitación de dos incisivos inferiores (3.1 y 4.1$)$ con un único implante.

\section{Caso clínico}

Paciente de 54 años acude a consulta con absceso en la zona de 3.1 y 4.1 , donde anteriormente ya se había realizado una apicectomía.

Tras la exploración, se observa imagen apical en la zona de 4.1 y 3.1, además de un defecto óseo vertical y horizontal con
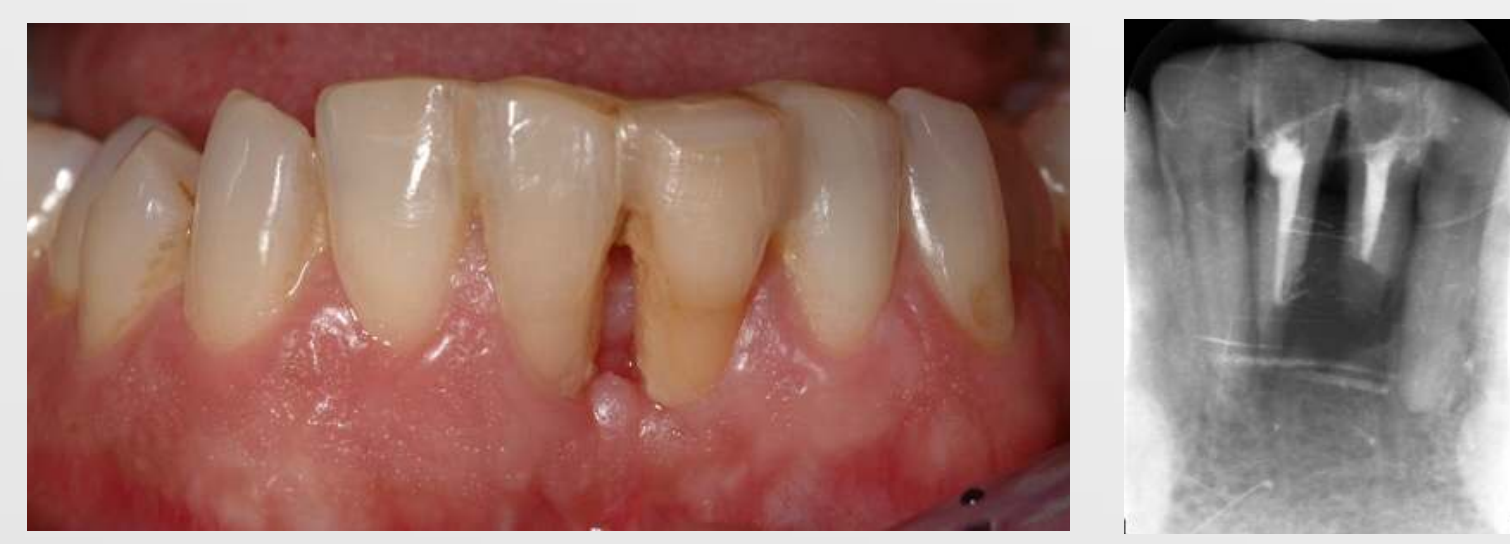
pérdida de la tabla ósea vestibular y lingual.
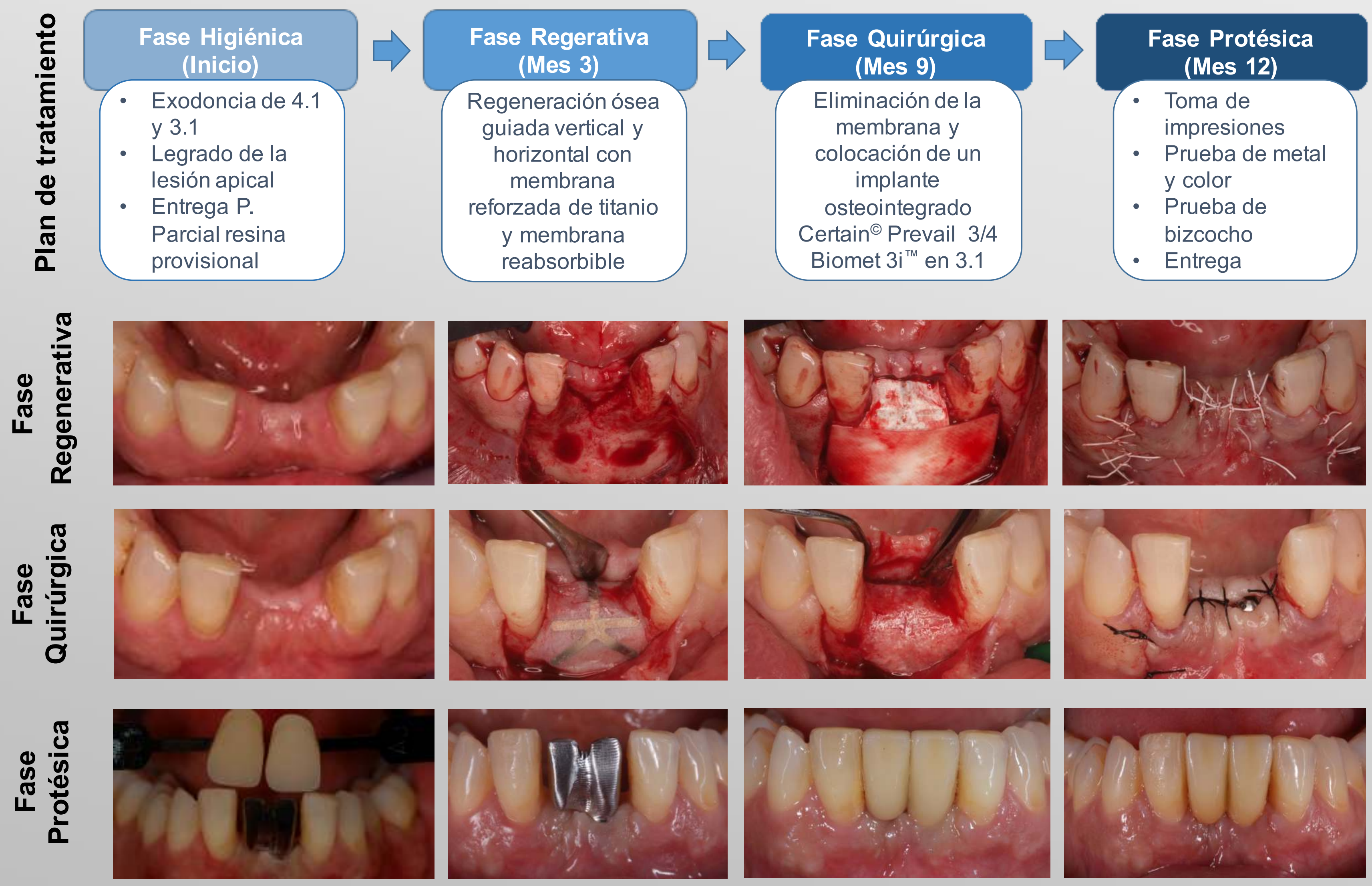

\section{Conclusiones}

La rehabilitación de dos incisivos inferiores mediante la utilización de un único implante es un tratamiento fácilmente realizable, predecible, económico y con buenos resultados, tanto estéticos como funcionales.

\section{Bibliografía.}
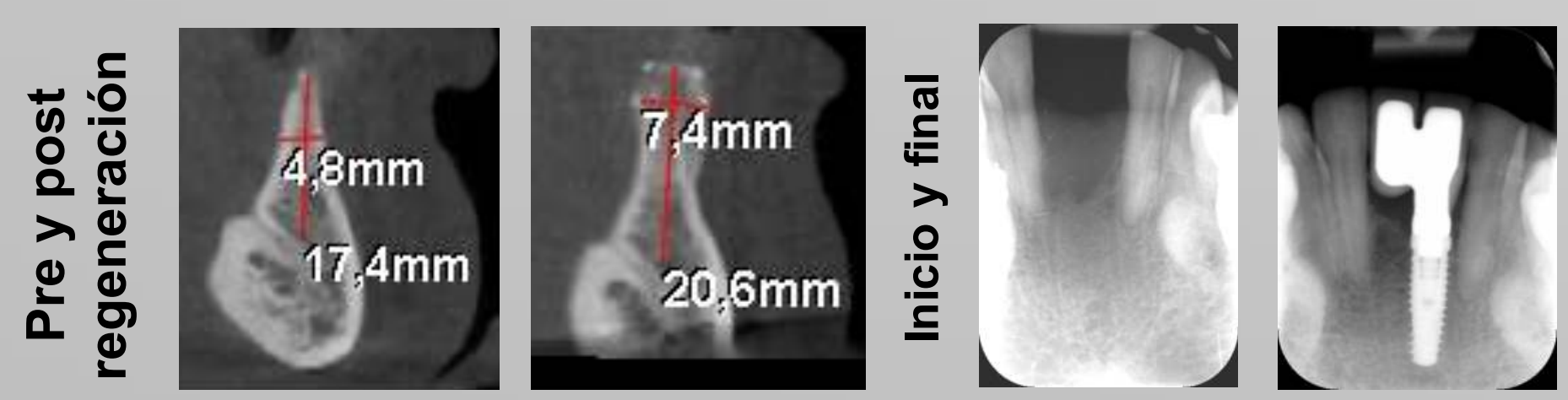

1. Buser D, Chappuis V, Bornstein MM, Wittneben JG, Frei M, Belser UC. Long-term stability of contour augmentation with early implant placement following single tooth extraction in the esthetic zone: a prospective, cross-sectional study in 41 patients with a 5- to 9-yearfollow-up. J Periodontol. 2013;84:1517-1527.

2. Soldatos NK, Stylianou P, Koidou VP, Angelov N, Yukna R, Romanos GE. Limitations and options using resorbable versus nonresorbable membranes for successful guided bone regeneration. Quintessence Int. 2017;48(2):131-147.

3. Van Nimwegen WG, Raghoebar GM, Tymstra N, Vissink A, Meijer HJA. How to treat two adjacent missing teeth with dental implants. A systematic review on single implantsupported two-unitcantileverFDP's and results of a 5-year prospective comparative study in the aesthetic zone. J Oral Rehabil.2017 Jun;44(6):461-471. 